\title{
LA BIBLIOTECA DE MARTÍN SARMIENTO. DISTINGUIR PARA UNIR
}

\author{
Concha Varela-Orol* \\ Universidade da Coruña \\ Rocío Ameneiros-Rodríguez ** \\ Universidade da Coruña
}

L'univers n'est qu'un vaste océan, sur la surface duquel nous apercevons quelques îles plus ou moins grandes, dont la liaison avec le continent nous est cachée. (Jean d'Alembert, Discours préliminaire de l'Encyclopédie)

\begin{abstract}
Resumen: Se estudia el catálogo de los libros de la biblioteca de Martín Sarmiento redactado por el propio autor, especialmente la ordenación temática del mismo y la disposición de los libros dentro de cada materia, relacionándolas también con otros sistemas de clasificación propuestos por él. Finalmente se ofrece una visión global de la composición de la biblioteca de acuerdo a las cinco grandes clases en que se dividía la ciencia en el siglo XVIII. Se concluye que ordenación de los libros y composición de la biblioteca son significativas del propio autor, de sus preocupaciones por el método y las novedades científicas, y de la fragmentación de la ciencia que caracteriza al siglo XVIII.
\end{abstract}

Palabras clave: Martín Sarmiento; bibliotecas particulares; clasificación de libros; ilustración española.

Title: MARTIN SARMIENTO’S LIBRARY. DISTINGUISHING TO UNITE.

Abstract: We study the catalogue of Sarmiento's library written by the author, especially its thematic planning and the layout of books within each subject. We also relate this to other classification systems proposed by him. Finally, we offer an overview of the composition of the library according to the five major classes in which science was divided in the XVIIIth century. We conclude that both arrangement of books and library composition are representative of the author himself, of his interest on the method and on scientific latest innovations, and of the fragmentation of science that characterizes the XVIIIth century.

Keywords: Martín Sarmiento; private libraries; classification of books; Spanish enlightenment.

\section{INTRODUCCIÓN}

Entre las más importantes bibliotecas españolas del siglo XVIII constituidas por un particular está la que se ubicaba en la celda del ilustrado benedictino Martín Sarmiento en el monasterio madrileño de San Martín. Su importancia fue destacada por Campomanes (García Morales, 1968-1972, p. 121), que la sitúa entre las más importantes de España, junto a las de Manuel Ventura Figueroa, Felipe de Castro, Mayans, etc.

Sarmiento defendió la importancia de los libros y la lectura en la vida de la celda, y la necesidad de que los novicios benedictinos fuesen educados en el gusto de leer, frente a un método de enseñanza basado en la memoria, afirmando que "...la tal qual afición que tengo a leer un libro, no se me ha pegado por lo que me hicieron escribir, leer, y estudiar de memoria, sino por lo que, por mi mismo, y al escondite, leí a vulto, en uno y otro libro, que podía haver a las manos" (Sarmiento, 1752, f. 188v.).

En este gusto por la lectura hay que buscar el origen de su impresionante biblioteca. El propio Sarmiento es consciente de su importancia, y así lo muestra en una de sus cartas, cuando dice en 1764 “...que no siendo yo mas que un pobre Monxe Benedictino particular sin oficio ni beneficio, sin rentas ni pensión, havia logrado la fortuna de poder juntar en cuarenta años por acasos fortuitos una numerosa librería de 6.500 volúmenes en todo genero de materias Divinas y Humanas...” (Monteagudo, 2002a, p. 215).

De la existencia de su biblioteca Sarmiento dejó abundantes noticias en sus escritos. Hacia 1755 nos da indicaciones de sus primeras adquisiciones de libros: "Hace ya 38 años que, en Salamanca, compré el juego de

\footnotetext{
* concepción.varela@udc.gal

** rocio.ameneiros@udc.es
}

Recibido: 04-11-2015; 2 ${ }^{a}$ versión: 11-01-2016; aceptado: 15-01-2016.

VARELA OROL, C. y AMENEIROS RODRÍGUEZ, R. La biblioteca de Martín Sarmiento. Distinguir para unir. Anales de Documentación, 2016, vol. 19, nº 1. Disponible en: http://dx.doi.org/10.6018/analesdoc.19.1.242061. 
Descartes. Y, aunque lo entendía poco, le sacudí tantas veces el polvo...” (Sarmiento, 1995, p. 96). Así pues, desde muy joven comienza Martín Sarmiento a adquirir libros, financiados, según él mismo confiesa, con los trabajos realizados dentro y fuera de la Orden, tales como la catalogación de la biblioteca de la Catedral de Toledo o los diversos informes que realiza para los círculos cortesanos, así como con los beneficios de la obra que había publicado en defensa de Feijoo, la Demostración crítico-apologética del Teatro Crítico.

En diversas ocasiones hace Sarmiento referencia a que con gusto dejaría su biblioteca a la ciudad de Pontevedra. Pero sabe que ha de quedar para su convento de profesión, tal y como estaba establecido por un capítulo general celebrado en 1524. Y así escribe al Nuncio en 1748: "La porcioncilla de libros que tengo ad usum en mi celda solo los compré con el fin de hacer más numerosa y universal la Bibliotheca de este Monasterio de San Martín,... a la cual pertenecen de derecho después de mis días” (Monteagudo, 2002b, p. 17-18).

Sin embargo, después de su primer viaje a Galicia, cuando los libros parecen convertirse en motivo de problemas más que de gozo, también barajó deshacerse de la biblioteca para volver a su tierra:

Ese [el viaje] depende aún de desembarazarme del todo de mi librería, que ni puedo portear, ni quiero dejar a discreción de la polilla. Hago las diligencias por si salta algún indiano que quiera comprarla toda, o casi toda, con el fin de poner a censo a favor de este Monasterio el capital, usufructuando yo los réditos por mi vida, pues haré que basten para mi manutención, agregado yo a un Monasterio de Galicia. Hace más de veinte años que estoy pensando en esto (Sarmiento, 1995, p. 140).

A la muerte de Sarmiento su biblioteca se incorporó a la del Monasterio de San Martín de Madrid, que hubo de enriquecerse considerablemente con la incorporación de los libros de nuestro autor, lo que no deja de advertir Antonio Ponz (1782, p. 206): “La Biblioteca del Monasterio de S. Martín es una de las mejores de las Comunidades de Madrid, particularmente desde que se ha incorporado en ella la selecta, y copiosa que llegó a juntar el P. Sarmiento, cuyo Retrato pintado por Don Gregorio Ferro se ha colocado en ella”.

Los acontecimientos históricos que desencadenarían la caída del Antiguo Régimen tuvieron un fuerte impacto sobre el monasterio benedictino y su biblioteca corrió la misma suerte. Durante la Invasión francesa y el Trienio Liberal gran parte de la biblioteca monacal desapareció, al tiempo que su iglesia, donde estaba enterrado Sarmiento. Años después, la desamortización de 1835 acabaría trasladando algunos de los restos de la biblioteca del monasterio a la Biblioteca Real, como señala Basilio Sebastián Castellanos, que afirma haber recogido parte de sus fondos (Castellanos de Losada, 1865, p. 420-421). Pero por lo que afecta a los libros de Sarmiento, algunos debieron de pasar a manos privadas, como tan frecuentemente ocurrió en las bibliotecas desamortizadas, ya que libros de nuestro autor se incorporaron posteriormente a bibliotecas institucionales como la BNE, llegados a través de otras procedencias, especialmente entre los libros de Pascual de Gayangos, a veces después de pasar por propietarios anteriores. Así el manuscrito sarmentino Visita y Consejo de médicos de Estéfano de Sevilla fue primero propiedad de Antonio Hernández Morejón y posteriormente llegó a la BNE de manos de Gayangos. En otros casos, sus libros parecen haber salido de España, como es el caso de su Códice Calixtino (Díaz y Díaz, 1988).

Dentro de la variedad de aportaciones realizadas por Sarmiento a la filología, la historia literaria, la historia natural, la pedagogía, etc., de las que se han ocupado distintos autores, sus reflexiones y propuestas relativas a las ciencias documentales han sido objeto de poca atención, aunque es posible rastrear algunos trabajos sobre las mismas ya desde finales del siglo XIX, y hay noticias sobre ellas entre los investigadores de su obra. Menos todavía son los estudios realizados sobre su importante biblioteca.

El primer escrito sobre la biblioteca del benedictino se debe a su biógrafo Antolín López Peláez (1895) con noticias biográficas sobre las relaciones de Sarmiento con los libros e indicaciones de algunas de sus lecturas. El segundo es obra de Dalmiro de la Válgoma (1971-1972), con información sobre el donante del catálogo a la biblioteca a la Real Academia de la Historia, e información sobre los exlibris de Sarmiento.

En 1973 se publica el que es sin duda el texto más citado sobre la biblioteca sarmentina. Se trata del trabajo de Giovanni Stiffoni (1973), en el que se analizan los libros de tres áreas temáticas de su biblioteca: la Historia literaria/Juegos grandes y periódicos, Filosofía moderna y Política, Económica y Comercio. Stiffoni resalta el valor del catálogo redactado por el benedictino como aportación al conocimiento de las fuentes empleadas en sus obras impresas. Pero su trabajo destaca, especialmente, la importancia de la biblioteca de Sarmiento para la reconstrucción de las fuentes bibliográficas empleadas por Feijoo, lo que le desvía del análisis del interés de la biblioteca como tal y para el conjunto de la obra de nuestro autor. 
El objetivo de este artículo es analizar diversas noticias que nos deja Sarmiento sobre su biblioteca y especialmente el orden dado a los libros en su catálogo (Sarmiento, 174?-176?), relacionándolo con otras clasificaciones propuestas por el autor y atendiendo a la concepción que subyace respecto a la taxonomía de la ciencia que es posible derivar de este análisis. Se busca también aportar una visión global de la composición de la biblioteca de Sarmiento, señalando los grandes pesos de la misma, y su correspondencia con las materias que Enciso Recio (2002) ha considerado significativas en la caracterización de una biblioteca ilustrada.

\section{EL CATÁLOGO: LEYENDO EL MANUSCRITO}

El manuscrito autógrafo del catálogo de la biblioteca de nuestro autor (Sarmiento, 174?-176?) comienza con una anotación, firmada por Vicente Vázquez Queipo ${ }^{1}$, en la que explica que el manuscrito le fue regalado por su tío Vicente Valcárcel y Vázquez, abad benedictino de Celanova (Ourense), después de haberlo adquirido a un abogado de la misma villa. La nota, fechada en 1862, corresponde a la donación que su poseedor hace a la Academia de la Historia en orden a enriquecer su colección de escritos sarmentinos. De acuerdo a Vázquez Queipo, hace la donación del manuscrito porque por esos años la Academia intentaba la publicación de los manuscritos de Sarmiento (Vázquez Queipo, 1865). Este interés de la Academia de la Historia en el siglo XIX por la obra de Sarmiento contrasta con lo ocurrido en 1791, cuando Benito Cano solicita licencia para la publicación del Catálogo de algunos libros curiosos y selectos (Sarmiento, 2002a) y la Academia se la niega porque "no tiene método, gusto ni la crítica que debía acompañar a una instrucción bibliográfica” (Aguilar Piñal, 1981-2001, p. 577).

El primer folio escrito por Sarmiento contiene una explicación de los exlibris empleados por él. Algunos libros tienen como exlibris su firma. Pero también usa una "señal oculta” que describe detalladamente. Este segundo sistema de marcar sus libros es uno de los múltiples juegos numerológicos que Fray Martín realizaba, como nos deja patente en esta ocasión desde las primeras líneas. Se trata de una señal realizada con una aguja bajo determinadas letras, que leídas juntas forman la frase: "Fray Martín Sarmiento, Benedictino”, texto que llevaban también los libros con firma expresa. Las señales ocultas comienzan en el folio correspondiente al número que da la suma de las letras de su nombre, y a partir de ese resultado, sumando el número de letras de cada una de las palabras de su nombre, se obtendrá el folio en que seguirán apareciendo las señales. Este ocultamiento de los mensajes mediante juegos numéricos, aunque sean explícitos, no es la única vez que es empleado por Sarmiento. Así en las Reflexiones literarias (Sarmiento, 2002b, p. 57) propone como inscripción para la Biblioteca Real el versículo 9:4 de los Proverbios: "Si quis est parvulus veniat ad me et insipientibus locuta est”, del que explica que tomadas las letras con significación en el sistema de numeración romano, y mediante las sumas que Fray Martín señala, se obtiene el año 1742, año en el que se idea el edificio. Similares combinaciones aparecen también en el Sistema de adornos del Palacio Real (Sarmiento, 2002c), y en los Apuntamientos para realizar una empresa... (Sarmiento, 1734?). Sabemos pues que estas artes eran del gusto de Sarmiento, y podemos corroborarlo leyendo el catálogo de su biblioteca. Todos estos mensajes ocultos en clave numérica probablemente guardan relación con su esfuerzo por crear una lengua científica universal, o, como él prefería decir, “general”, y su utilización del lenguaje matemático para construirla.

¿Por qué nuestro autor toma tan grandes cuidados con sus libros que al fin y a la postre solo posee ad usum? La misma pregunta es pertinente respecto al propio catálogo de sus libros, en cuya redacción tuvo que invertir muchas horas, describiendo una colección que seguramente él controlaba sin necesidad de tenerla catalogada. Si además tenemos en cuenta la redacción de un texto autobiobibliográfico, el Catálogo de los pliegos (Sarmiento, 1767), se amplían las preguntas sobre con qué finalidad elaboraba Sarmiento estos instrumentos bibliográficos: ¿esperaba Fray Martín ser reconocido a su muerte por sus libros y su trabajo intelectual, que en vida nunca quiso editar?, ¿escribía estos instrumentos para facilitar el trabajo a su propio monasterio cuando hubieran de hacerse cargo y conservar sus manuscritos y libros? O, ¿buscaba convertirse en un modelo pedagógico para los futuros miembros de su Orden, tal y como Fernando Bouza (2001) encontró que ocurría con las biografías manuscritas, auténticos manuales de corte en el Siglo de Oro? Recordemos que en carta al abad del monasterio lucense de Samos da indicaciones sobre la manera en que se debe elaborar la "noticia hystorial” de Feijoo, y además considera muy útil que se haga un "Índice individual de toda su librería”, y que a su muerte haya un día al año dedicado a ofrecerle un oficio solemne, como modo de recordarle siempre, y anota “...si yo hiciese la cesión en vida pondría el propuesto requisito en la escritura” (Sarmiento, 1750).

A pesar de la humildad de que permanentemente hace gala nuestro benedictino, parece probable que él esperase también su biografía, la cual, al menos de su vida intelectual, deja esbozada en el Catálogo de los pliegos. Deja también ya hecho el índice de su librería. El resto no está en sus manos. A la vista de lo dicho, las respuestas a las preguntas que atrás consideramos, no contradictorias sino complementarias, creemos que son afirmativas en los tres casos. 
En el Catálogo de los pliegos el benedictino señala que en 1750 "comenze a formar, y a Escribir el Indize Individual de los 6y500 volumenes de libros”. En realidad el catálogo de la biblioteca sarmentina consta de dos partes: la primera es lo que hoy denominamos un índice de autores, la segunda está formada por lo que en la actualidad llamamos catálogo.

Después de los preliminares señalados, la redacción del manuscrito comienza bajo el título siguiente: “Catalogo de los Autores de quienes yo Fr. Martín Sarmiento, Benedictino, tengo ad usum, ò todas sus obras, ò parte de ellas, ò algún tomo suelto, y separado. Hoy [blanco] de [blanco] de 174 [blanco]”. Sarmiento debió dejar la fecha con estos blancos para cubrirlos a la finalización de este índice alfabético de autores. Por el contrario, al referirse al catálogo propiamente dicho en el Catálogo de los pliegos lo denomina "Índize Individual", dejando claro que se refiere al catálogo de su biblioteca, pues añade: "Và por Ciencias y Materias”. La aplicación de los términos "Catálogo” e "Índice” fluctúa todavía en el siglo XVIII, como puede verse en los Diccionarios de la Academia española (Academia). El primero es definido por el Diccionario de Autoridades, y de forma similar por las ediciones posteriores, como "Lista, memoria o inventario de Personas, cosas o sucessos puestos en orden", mientras que “Índice” no aparecerá en el Diccionario académico hasta 1803 con la acepción de "Lista, o enumeración breve, y por orden alfabético, de libros, capítulos o cosas notables” (Academia).

De todo esto, cabe deducir que por los años 40 Fray Martín realiza un índice de los autores de los que posee obras en su biblioteca. En este índice, en cada una de las secuencias alfabéticas, hay dos partes: una primera relación de autores perfectamente alfabetizada, y un "Suplemento a[ñ]o 1750", que parece redactado en sucesivos momentos, ya que entre las distintas entradas de una misma letra no se respeta el orden alfabético. El conjunto de estos datos indica que la relación de los autores de los que poseía obras fue redactado con anterioridad al catálogo, en sentido actual, de su biblioteca, y que en el año 1750 cuando comienza la catalogación, comienza también a completar el índice de autores de la década de los 40, lo que seguirá haciendo en años sucesivos. Si esto fuese así, estaríamos en situación de conocer los libros poseídos, y posiblemente leídos, por Sarmiento antes de 1750, y la incorporación sucesiva de autores en los últimos 20 años de su vida.

\section{EL ORDEN DE LOS LIBROS}

Sarmiento nos ha dejado diversas afirmaciones respecto a la disposición de los libros en su catálogo. Sirva de ejemplo:

Yo tengo coordinados mis libros en los estantes; y cuando algún extraño curioso viene a mi Celda a buscar alguna noticia que necesita de pronto, sé que ni en una semana la encontraría por sí, y no necesito levantarme de la silla para dársela registrada al punto, sobre mi mesa (Sarmiento, 1752, f. 14v.).

La cita nos aporta tres informaciones de interés: la primera que la disposición física de sus libros está hecha con método; la segunda, que el orden ha sido diseñado con el objetivo de acceder con facilidad a la información; la tercera, que la disposición de los libros no debía corresponder a los sistemas de ordenación más habituales, ya que los "curiosos" no se manejarían con facilidad para recuperar la información. Parece razonable pensar que libros en los estantes y catálogo tendrían el mismo orden, pero realmente no lo sabemos. En todo caso, sin duda el catálogo responde a los dos primeros objetivos, ya que está ordenado por materias e introduce una relación inicial de autores, es decir incorpora la posibilidad de recuperar por los dos puntos de acceso fundamentales en las bibliografías del momento, aunque el índice de autores tiene un uso limitado ya que no permite llegar del autor al título o títulos. El cuidado puesto en el acceso a la información se refuerza también a través de referencias temáticas presentes a lo largo del mismo. El sistema era similar al propuesto por Adrien Baillet, cuyos Jugemens des Savans sur les principales ouvrages..., obra que poseía Sarmiento entre sus amplias colecciones de Historia literaria, proponían un orden alfabético de materias que constituiría el “verdadero catálogo” o “diccionario razonado” de una biblioteca, seguido por un índice alfabético de autores (Verner, 1968), aunque nuestro autor invierte el orden de ambas partes.

El orden temático empleado por Sarmiento en los catálogos y bibliografías redactadas a lo largo de su vida son muy variables. Si bien, la incluida en su primer catálogo conocido, el de la biblioteca de la Catedral de Toledo (Sarmiento, 1727), podría responder o estar condicionado por el orden existente cuando él y Diego Mecolaeta se incorporan a los trabajos catalográficos, en 1743 en las Reflexiones literarias (Sarmiento, 2002a) propone para la Biblioteca Real cuatro grandes clases: teología, historia, jurisprudencia y artes y ciencias. Frente al orden de los saberes que los libreros parisienses estaban difundiendo desde principios de siglo con cinco grandes clases o facultades (teología, jurisprudencia, ciencias y artes, bellas letras e historia), un sistema que acabará convirtiéndose en 
hegemónico en las bibliotecas europeas, Sarmiento emplea los cuatro grupos señalados, posiblemente para adaptarlo a la arquitectura que propone para la Biblioteca Real, ya que no hemos de olvidar el carácter simbólico que la disposición de los libros tenía en las bibliotecas públicas.

Cuando en 1748 redacta el Catálogo de algunos libros curiosos y selectos (Sarmiento, 2002a) el orden en que dispone los libros seleccionados será otro. El esquema presentado aquí por Sarmiento varía considerablemente respecto al anterior. Nuestro autor propuso este orden para una colección específica, la del Marqués de Aranda, pero con numerosas referencias a las bibliotecas públicas. El carácter iniciático que toda clasificación de libros supone descansa aquí sobre la antigüedad clásica, sigue con las colecciones que él aconsejaba para poseer muchos autores en pocos tomos, y, si exceptuamos los grupos finales que constituyen una especie de miscelánea sobre libros raros y de singular valor, finaliza con la Biblia, su interpretación y “gramáticas y lexicones”, un tema nunca menor en Sarmiento.

Ninguno de estos modelos fue el elegido para disponer los grupos temáticos del catálogo de sus libros, que puede verse en el Apéndice I, junto al número de registros y volúmenes incluidos en cada epígrafe. Sarmiento inicia su catálogo por la teología, como era habitual en los sistemas de clasificación bibliográfica de la Europa del Antiguo Régimen. En los catálogos de bibliotecas institucionales, como las de las Universidades de Salamanca o Santiago de Compostela, de bibliotecas particulares, como el redactado por Montfaucon de los fondos manuscritos griegos del obispo de Metz Henri-Charles de Coislin, bibliotecas selectas como la incluida por Mabillon en la segunda edición del Tratado de los Estudios monásticos, en catálogos de libreros como los del francés Gabriel Martin o el del holandés Moetjiens utilizado por nuestro autor, la teología, y concretamente la Biblia era el principio del conocimiento.

A continuación de sus valiosas colecciones bíblicas, sigue un subepígrafe de Concordancias, y como epígrafes separados Aparato, Critica y Erudición de la Escritura, Concilios, Padres y Dogmáticos y Teología escolástica y moral, tal y como ocurría en muchos de los sistemas citados.

Pasado este lugar común en los sistemas clasificados del momento, Sarmiento desarrolla una ordenación del catálogo propia, ya que como señalará años más tarde (Sarmiento, 1762, f. 458) si diez o doce hombres doctos colocasen los libros de una biblioteca utilizarían otros tantos sistemas distintos. La no adopción de modelos fue defendida por Sarmiento en el mismo texto, siguiendo su argumentación sobre los sistemas de clasificación ahora aplicados a los vegetales, como puede verse en la siguiente cita:

Muy rudo há de ser, el que haviendo visto, tocado, manoseado, y observado, por si mismo, muchisimos vegetables; necesita que otro le presciba el Methodo, con que los há de colocar, á distribuir por Clases. Siempre hé abundado en el sentido de que el methodo, que uno há de seguir en cualquiera Estudio, no há de ser mendigado de otro [...] El methodo para ser fructuoso, y util, le deve formar cada uno, segun su modo; y segun la multitud de noticias que tuviere (Sarmiento, 1762, f. 463v.).

El sistema elegido por Sarmiento para el catálogo de sus libros es descrito por él mismo, como ya hemos señalado: "Va por ciencias y materias" (Sarmiento, 1767). Y efectivamente existe en él una secuencia de materias ordenadas alfabéticamente, que va desde el epígrafe Astrología hasta el epígrafe Vidas. Recordemos que por los mismos años la Encyclopédie francesa, pese a los esfuerzos del Discours préliminaire (Alembert, 1999) de desarrollar una relación entre las ciencias de modo que diese lugar a una unidad superior y totalizante representativa del conjunto del conocimiento que correspondiese a la nueva cosmovisión que había propiciado el desarrollo científico, no fue capaz de llevarla a la práctica, como se ve en el cuerpo de la obra al adoptar el orden alfabético para los lemas. Como veremos posteriormente Sarmiento va a intentar paliar esta dificultad no sólo en el inicio del sistema, como hemos señalado, sino también en su cierre.

La secuencia alfabética sarmentina no carece de alteraciones, que pensamos que se pueden explicar bien como subdivisiones temáticas, bien como representación de las claras relaciones que ve Sarmiento en estos epígrafes ajenos al orden alfabético general con los epígrafes inmediatamente anteriores. Así, después de la división Erudición oriental, Sarmiento sitúa el epígrafe Buxtorfios iniciando un nuevo folio; este epígrafe va seguido de Hottinger, Seldeno, Relando, y Vossios, sin iniciar nuevos folios. Todos ellos constituyen autores o familias de autores de conocidos orientalistas, y por tanto los interpretamos como subepígrafes del epígrafe Erudición oriental.

Otra alteración del orden alfabético es la de situar a Johann Albert Fabricius a continuación de Johannes van Meurs. Sarmiento había situado a ambos humanistas en el Catálogo de algunos libros curiosos y selectos entre los Autores Polígrafos: “...los que han escrito muchos tomos en un mismo asunto, o de muchos asuntos en bastantes tomos” (Sarmiento, 2002a). El paralelismo de los trabajos de ambos humanistas explica su posición contigua en el catálogo. 
Relaciones temáticas similares se pueden encontrar entre Geometría práctica, estática y mecánica y la aparentemente desordenada Música teórica y práctica, ambas entendidas en el período como matemáticas aplicadas o “mixtas"; y entre Óptica, Perspectiva y Pintura y la también aparentemente desordenada Arquitectura civil y militar, fuertemente vinculada a la Óptica desde el siglo XVI, lo que se plasmaba hacia 1757 en la propuesta del Conde de Aranda para que todas ellas formasen parte de los estudios arquitectónicos (García Melero, 1997, p. 168-169). En todo caso, ambas materias eran también “matemáticas mixtas”.

Podemos decir que en el grueso del catálogo sarmentino las distintas ciencias y materias se sitúan en general a igual nivel jerárquico y se ordenan alfabéticamente. Pero una lectura cuidadosa de la fuente muestra que los epígrafes que corresponden a estas materias se indican en unas ocasiones con la primera palabra en letras mayúsculas y otras veces en minúsculas, lo que conociendo a nuestro autor nos parece significativo, teniendo en cuenta su afirmación en relación a la división "por ciencias y materias”.

Si atendemos al Diccionario de Autoridades (Academia), encontramos que "ciencia" se define como “Conocimiento cierto de alguna cosa por sus causas, y principios...”, y unos años después, en el Diccionario académico de 1780, se modifica el texto para ser "Sabiduría de las ciencias humanas por principios ciertos, como los de la Matemática...”. En el orden sarmentino tal definición corresponde a los epígrafes indicados en mayúsculas.

En ambos diccionarios, entre las acepciones del lema "materia” están: "Se toma asimismo por assunto de que se trata...", y "En las Universidades se llama el escrito que hacen los estudiantes dictado por el Maestro desde la cathedra, que regularmente en el tiempo de un Curso se compone de una de las partes subalternas de la ciencia que se lee...”. Entendemos que las ciencias de nuestro autor son aquellos epígrafes cuya primera palabra está en letras mayúsculas, en una ocasión la segunda, mientras las materias son los epígrafes en minúsculas, formados bien por asuntos tratados sin método científico, bien constituidos por partes de una ciencia.

Ahora bien, la lectura del Apéndice I al final de este artículo, requiere atención al estado de la ciencia a mediados del siglo XVIII. Puede sorprender que el epígrafe Astrología y Artes Vanas figure con la primera palabra en mayúsculas. Pero ha de tenerse en cuenta la confusión que entre los términos astrología y astronomía existía todavía en el siglo XVIII (De Beni, 2014), pese a que ya Isidoro de Sevilla había intentado establecer la diferencia semántica de ambos. De acuerdo a De Beni, los primeros diccionarios de la Academia española incluían dentro de la astrología la natural "la que solo se emplea en el conocimiento de las influencias celestes por observaciones de cosas naturales", y la judiciaria, relacionada con la adivinación. Esta última ha de corresponder para Sarmiento a la segunda parte de la denominación del epígrafe "artes vanas”. Pero ambas todavía en el diccionario académico de 1770 se definen como “ciencia”, y no será hasta el de 1822 cuando la voz astrología se limite a la astrología judiciaria, ahora calificada como "vana ciencia”, y casi simultáneamente se introduzca el término meteorología, representado en este epígrafe del catálogo de la biblioteca de Sarmiento por distintos textos de efemérides astronómicas.

Por otra parte, Sarmiento incluye entre los epígrafes Cosmografía, Astronomía y Gnomónica y lo hace en letra minúscula, al igual que la Geografía y Naútica, la Geometría Práctica. Estática y Mecánica, o la Cirugía. Pensamos que estos casos son perfectamente explicables a partir de una de las acepciones de la palabra "materia" del Diccionario de Autoridades que hemos citado, la que hace referencia a las partes subalternas de una ciencia, las primeras de las matemáticas, la última de la medicina.

Analizando la secuencia alfabética desde un punto de vista formal, nos encontramos con 30 epígrafes con la primera palabra en mayúscula y 35 en minúscula. Estos últimos es posible reducirlos a 30, teniendo en cuenta que 5 no inician folio, y por tanto, pueden leerse como subepígrafes. Recordamos ahora el curioso exlibris que sitúa al principio del catálogo que nos habla de una señal que oculta su nombre "Fray Martín Sarmiento, Benedictino” compuesta de 30 letras.

Finalizada la parte que entendemos como alfabética en el catálogo, este se cierra con las Obras de los monjes de Saint-Maur, y tres autores Athanasius Kircher, Gaspar Schott y Juan Caramuel. Los trabajos de los maurinos han influido considerablemente en Sarmiento ${ }^{2}$, y en sus escritos no faltan referencias a las grandes obras abordadas por esta Congregación que deben de servir de modelo a los benedictinos españoles. En cuanto a los tres últimos son autores polímatas que mantuvieron relaciones a lo largo de su vida, ya que Schott era discípulo de Kircher, y también Caramuel mantuvo correspondencia epistolar con este último sobre variados temas. Los dos primeros eran jesuitas, el cisterciense Caramuel se había formado con la Compañía, y fue siempre un firme defensor de ella, al igual que Sarmiento que dejó testimonio de su admiración por la labor intelectual de los jesuitas. Representantes de una ciencia barroca en transición, los tres participaron en la idea del saber como un todo, para el que se servían del método 
matemático que debería de permitir elaborar una ciencia universal en donde quedarían unificadas todas las ramas del saber.

Esta búsqueda de las relaciones entre las distintas ciencias no fue un problema menor para Sarmiento. En los últimos años de su vida reconoce la necesidad de una clasificación del saber “...si en esa serie, o cadena de cosas criadas supieramos que orden o lugar ocupa esta, o la otra cosa, no habría más que desear. Yo confieso que no lo sé, ni he sido Autor que haya pensado en ello; y es por que todo el Estudio es de voces, y no de cosas" (Sarmiento, 1769, f. 325). Pero en 1745 había dicho que eran las cosas las que le interesaban: "No busco en los libros palabras, sino cosas" (Sarmiento, 1775, p. XIII). Creemos que ambas citas explican el orden temático-alfabético y el cierre simbólico del catálogo de su biblioteca, retomando la vieja aspiración holista “distinguir para unir”, ahora realizada a través de los nuevos instrumentos que permitía la ciencia moderna.

Si analizamos la estructura interna de cada una de las temáticas que constituyen el eje de ordenación del catálogo, podemos concluir que Sarmiento comienza cada epígrafe con los libros de los autores más antiguos, al margen de cuáles sean sus fechas de edición, representando así la evolución histórica de la materia, en muchas ocasiones con colecciones de estos autores. Si tomamos como ejemplo el epígrafe Geografía y Naútica vemos que son los autores griegos y latinos los que inician esta materia (Estrabón, Pomponio Mela, Dionisio Periegeta, Pausanias, etc.), lo que no implica que libros de los mismos autores no se encuentren en otros lugares de la relación bibliográfica, como es el caso de Pomponio Mela, sin duda porque tales ediciones se incorporaron a la biblioteca sarmentina con posterioridad. Sarmiento aplica, pues, dentro de cada epígrafe una ordenación próxima a la propuesta en el Catálogo de algunos libros curiosos y selectos (Sarmiento, 2002a), ya que comienza por los autores de la antigüedad, representando cronológicamente la historia de la ciencia. En este texto al referirse a la composición de las colecciones señalaba que cada ciencia debe estar representada en la biblioteca por su historia y progresos, su diccionario, la bibliografía de sus autores, las colecciones de autores antiguos, sus historias principales, un compendio moderno, un curso entero, una compilación total de las materias, y los autores modernos reconocidos o raros. Creemos que los distintos epígrafes de su biblioteca responden bastante bien a este esquema compositivo.

\section{COMPOSICIÓN DE LA BIBLIOTECA}

En la carta al Nuncio arriba referida destaca la importancia dada por Sarmiento al carácter "universal” de su biblioteca, lo que volverá a reiterar en el Catálogo de algunos libros curiosos y selectos. Una universalidad que hay que entender en clave enciclopédica, y que nuestro autor exigía también cuando proponía el establecimiento de cátedras en la Universidad en facultades que no fuesen Teología, Medicina y Jurisprudencia: "Abranse los libros extraños y se verá unos son catedráticos de Historia, otros de Retórica, otros de Matemáticas, otros de Lengua griega...Todas estas cátedras, aunque fundadas, o están sin maestros, o sin discípulos en España...” (Sarmiento, 2002b, p. 129), o cuando proponía la creación de bibliotecas públicas, que se habían de caracterizar, frente a las bibliotecas de las comunidades, por ser enciclopédicas.

Esta biblioteca enciclopédica de acuerdo a su catálogo estaba formada por 2.535 autores, y 3.279 registros bibliográficos que suman un total de 5.525 volúmenes. Aunque los registros podemos asimilarlos a títulos de las obras, hay que considerar que el número de estos últimos es considerablemente superior, dado que Sarmiento posee numerosas colecciones, así como ediciones que contienen varios títulos del mismo o diferente autor, bien sea porque han sido publicados juntos, bien porque se trata de ejemplares facticios. El peso de estas circunstancias sobre la volumetría de la colección es considerable, ya que debe tenerse en cuenta que algunas colecciones comprenden textos de más de cincuenta autores. Por otra parte, hay que destacar que algunos libros, aparecen en distintos epígrafes del catálogo, y tenemos la impresión de que no siempre se trata de registros duplicados. Por tanto, las cifras indicadas deben ser vistas como aproximadas, tanto en el número de autores y títulos como en el de volúmenes. Y consideramos que no es preciso recurrir a otras explicaciones como la ausencia en el catálogo de los libros prohibidos (Santos Puerto, 2002) para que nuestras cifras se aproximen a las indicadas por Sarmiento en sus escritos. Porque de hecho Sarmiento ha anotado en su catálogo muchos libros prohibidos en el Índice inquisitorial de 1747, aunque no aparecen las figuras centrales de la Ilustración francesa, que por sus cartas sabemos que conocía. Pero no hemos de olvidar que Sarmiento manejó muchas otras obras que no estaban en su biblioteca, bien fuese en la biblioteca de su monasterio, de otros monasterios benedictinos, de la Biblioteca Real, a través de préstamos de otras personas (Sarmiento, $1730 \mathrm{~b}, \mathrm{f}$. 492v.), o incluso de bibliotecas privadas puestas en venta, como la de Manuel Pantoja (Sarmiento, 1775, p. 339). Y otras hubieron de conocerlas a través de obras y publicaciones que poseía en sus colecciones de novedades bibliográficas y de libros de viajes. 
En relación a la abundancia de colecciones hemos de destacar que la presencia de esta tipología documental es representativa del carácter enciclopédico de la propia biblioteca, ya que enciclopedias y colecciones, al igual que los propios catálogos, son significativas de la selección, compilación y sistematización del conocimiento características de las Luces.

Dada la imposibilidad de analizar aquí los distintos epígrafes temáticos, que, por otra parte, dificultarían una visión global de la biblioteca, reducimos los libros de esta a las grandes clases habituales en las bibliotecas institucionales y los catálogos de librería del período, usadas con frecuencia por los investigadores para analizar también las bibliotecas privadas, encontrándonos los datos de registros y volúmenes siguientes ${ }^{3}$ :

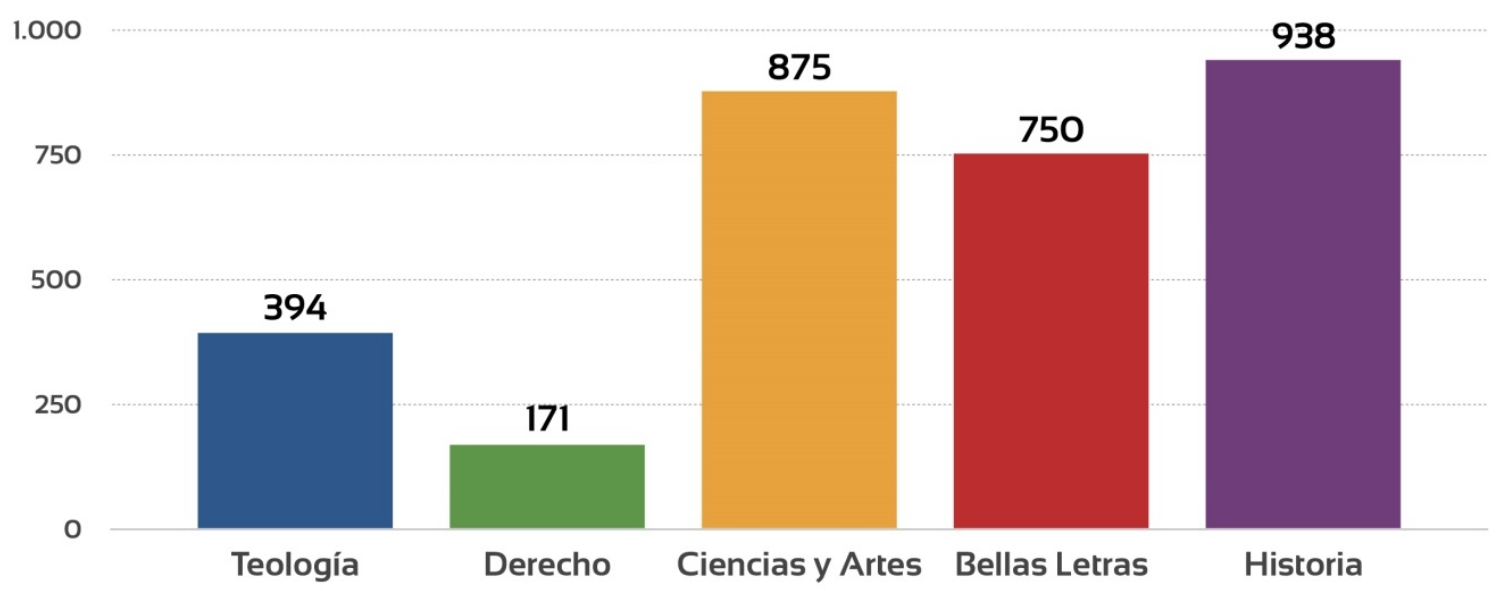

Figura 1. Registros bibliográficos.

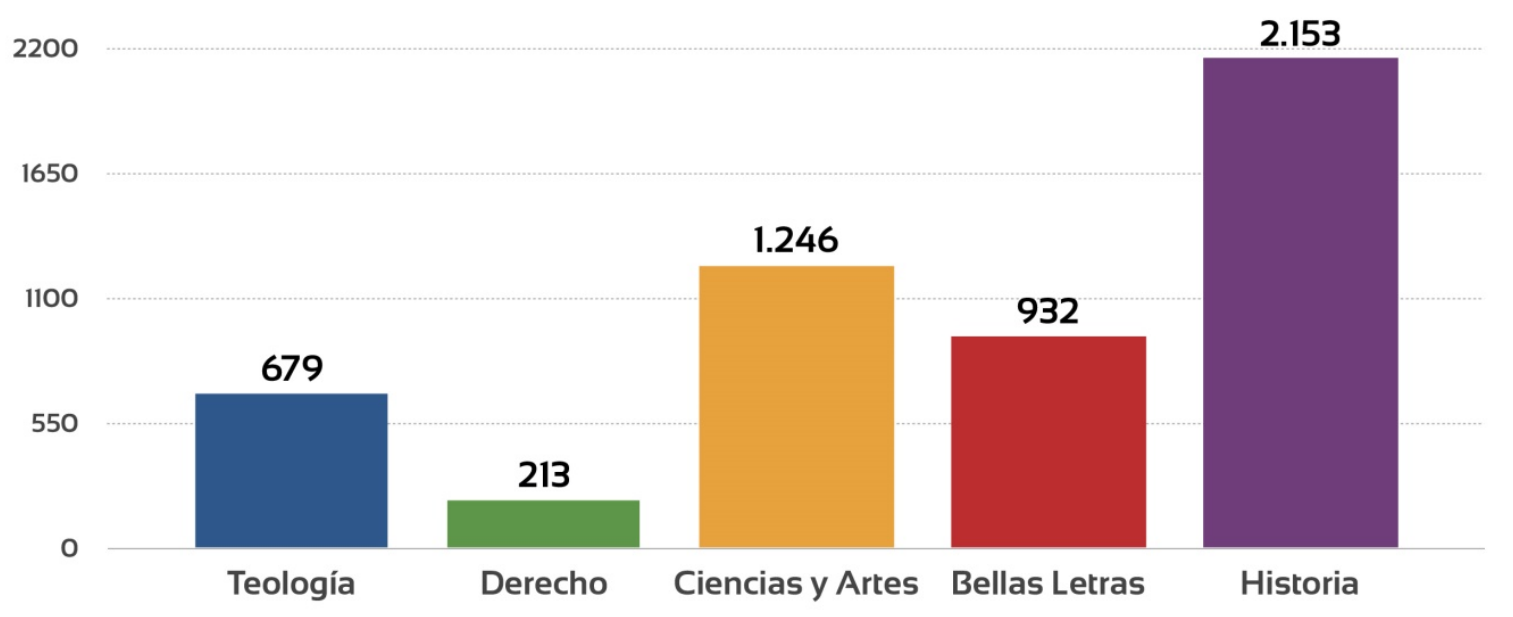

Figura 2. Volúmenes.

Enciso Recio (2002) ha señalado que las diferencias entre una biblioteca barroca y una ilustrada son relativas, aunque acabará caracterizando a las últimas. Siguiendo su exposición, la biblioteca ilustrada presentaría un descenso en los temas religiosos, aspecto destacable en la biblioteca de Sarmiento, donde esta colección representa el 12,6\% de los registros y el 13\% de los volúmenes, a pesar del fortísimo interés de nuestro autor por la Biblia, como es característico de los ilustrados españoles. Dentro de las colecciones bíblicas posee las Políglotas de Alcalá, Amberes, Ferrara, Walton y treinta y cuatro ediciones en lenguas semíticas, de las que veinticinco tienen el texto hebreo con y sin puntos. Esta presencia de las versiones orientales de los textos bíblicos se hace más patente al analizar las colecciones incluidas en los epígrafes de Concordancias y Aparato, crítica y erudición de la Escritura. Sin duda la posición de Mabillon sobre la centralidad de los estudios bíblicos en los estudios monásticos influyó en Sarmiento, 
pero además nuestro autor tiene un interés filológico en estos textos, que deja patente en muchos de sus escritos, como el trabajo sobre el castellano antiguo realizado sobre la Biblia de Ferrara (Sarmiento, s.f.). El uso de los textos bíblicos en apoyo tanto de su profesión religiosa como de sus trabajos filológicos le lleva a colocar algunos de los libros que figuran en el catálogo de la biblioteca entre las colecciones bíblicas, mientras que los mismos aparecen entre las filológicas en el Catalogo de libros curiosos y selectos (Sarmiento, 2002a).

El Derecho representa la clase con un número menor de registros (5,5\% del total) y volúmenes (4,1\% del total), y aunque las obras de derecho civil, que Enciso encuentra con mayor representación en la biblioteca ilustrada que en la barroca, son ligeramente inferiores a las de derecho canónico, en ambos hay una amplia presencia de las fuentes, por cuya recuperación en España aboga nuestro autor en las Reflexiones literarias (Sarmiento, 2002b). Destacan entre las obras de derecho civil las fuentes para el estudio del derecho español, cuyas recopilaciones valora como fuentes para el estudio de la lengua española (Sarmiento, 1775, p. 144). El debate entre la jurisdicción papal y el regalismo, paralelo a la controversia sobre el papado y las iglesias nacionales, está aquí representado por algunas obras incluidas en el epígrafe de Derecho canónico (Pierre Pithou, Jean Pierre Gibert, Louis Ellies Dupin), pero también en el apartado de Erísticos. Apologéticos y Satíricos (Pascal, Arnauld, Paolo Sarpi, Bossuet), sin que tampoco falten en ambos epígrafes obras antigalicanas.

“Los libros de Ciencia, Filosofía y Educación tuvieron clara acogida en el modelo ilustrado” (Enciso Recio, 2002). En Ciencias y Artes, con un 28\% de los registros del catálogo y un 23,8\% de los volúmenes, destaca la historia natural, botánica y agricultura, del mayor interés para los estudios de nuestro autor sobre los vegetales y la farmacología, pero también para la filología, la pedagogía y la agricultura. Entre las obras de historia natural destacan las obras de Bahuin, Tournefort y Linneo que cita con frecuencia en sus trabajos sobre las plantas. También la medicina, cirugía y química, y las matemáticas están ampliamente representadas en esta clase, y no faltan algunas obras de política y economía, esta última en fase de nacimiento en el siglo XVIII. Gran interés presenta la presencia en la biblioteca de las obras de Newton, a quien conoce y cita desde los primeros años de la década de 1730 (Sarmiento, 1730a, 1730b), y de quien se ha considerado a nuestro autor el primer introductor de su obra en España (Santos Puerto, 1997).

En cuanto a las Bellas Letras, con el 24\% de los registros y el 17,8\% de los volúmenes de la biblioteca de Sarmiento, la presencia de lenguas modernas y diccionarios y gramáticas es considerada por Enciso como parte del bagaje cultural ilustrado. La variedad de lenguas en que Sarmiento poseía este tipo de obras es patente con la sola revisión de los títulos de los epígrafes temáticos. Los fondos lingüísticos, especialmente lexicográficos, han de ser puestos en relación con el interés de nuestro autor por la etimología, la lexicografía en general, y la enseñanza de las lenguas, tema central en sus escritos pedagógicos. En cuanto a la literatura muestra Sarmiento el interés por los clásicos griegos y latinos y el humanismo, señalado por Enciso: los primeros, junto a los poetas castellanos e italianos tienen una importante representación en el epígrafe de Poesía de su biblioteca, pero hemos de recordar que los autores clásicos estaban muy bien representados en todos los epígrafes.

La Historia constituye la clase con mayor número de registros bibliográficos y volúmenes de la biblioteca de Sarmiento (30\% y 41,2\% respectivamente). Enciso Recio considera la historia de España, la historia eclesiástica, la geografía y los viajes como indicadores que caracterizan los fondos históricos de la biblioteca ilustrada. Pues bien, la historia de España como constructora de la identidad española en vinculación con la monarquía borbónica, tema muy presente en distintas propuestas sarmentinas, como su sistema iconográfico para el Palacio Real, tiene una buena representación en su biblioteca, con abundantes ediciones de crónicas de España e historias locales. También de geografía y viajes tiene nuestro autor unas buenas colecciones. Respecto a las últimas, mezcla de observación y experiencia, cabe señalar el papel que jugaban en la difusión científica, como muestran claramente las anotaciones sobre Newton tomadas por Sarmiento en la obra de René Auguste Constantin de Renneville (Sarmiento, 1730b). Igualmente sobresaliente es su colección de obras de historia literaria, donde se agrupaban las publicaciones periódicas que difundían en Europa las novedades científicas y editoriales (Journal de Savans, Acta eruditorum, la traducción al italiano de las Philosophical Transactions), junto a las bibliografías de Andreas Schott, Cornelius van Beughem, Maittaire, Antonio León Pinelo, y un largo etcétera, y a las historias de la imprenta de Jean le Caille y Prosper Marchand, o la obra de Burkhardt Gotthelf Struve.

\section{CONCLUSIONES}

Frente a otras bibliotecas particulares fruto de herencias o compras de bibliotecas completas, la biblioteca sarmentina es una biblioteca de elección, construida a lo largo de su vida fundamentalmente mediante adquisiciones a los libreros españoles y extranjeros, o libros llegados a través de su red de relaciones, e incluso mediante trueques. La 
redacción de su catálogo, como la de su autobibliografía, no deja de guardar relación con la afirmación del yo a que se remite la autobiografía en el siglo XVIII (Durán López, 2005).

Como hemos señalado el problema del método fue tratado por Sarmiento en distintos campos. Por ello el sistema de ordenación del catálogo, como la atención a la descripción bibliográfica más claramente explícita en el mismo, debió de ser objeto de reflexión para nuestro autor. Creemos que la ordenación temática del catálogo, además de mostrar la división y las relaciones entre las disciplinas que establecía Sarmiento, es significativo de su propia concepción del mundo. Al tiempo, en muchas de sus obras es clara la atención prestada al simbolismo, que se plasma en su gusto por los juegos numerológicos (exlibris, número de ciencias y materias), y también en el orden de sus libros.

El inicio del catálogo por la teología y en concreto por la Biblia, un lugar común en los sistemas de ordenación del siglo XVIII, es coherente con su vocación religiosa, la cual reiteradamente deja aparte del desarrollo de la ciencia, con la que era evidente chocaba en su siglo.

Pero no menos significativo es su cierre. No cabe duda de la influencia que los trabajos de la Congregación de Saint-Maur tuvieron sobre su propia obra, fueron en muchas ocasiones su fuente de inspiración y representaban como nadie a principios del siglo XVIII la aportación de los benedictinos a la cultura. La fidelidad a su Orden es patente en toda su obra. En cuanto a los tres autores finales, Kircher, Schott y Caramuel, conjugaban su ortodoxia religiosa con el experimentalismo y el método matemático de una ciencia en transición, como también ocurre en los escritos de nuestro autor, utilizándolos para caminar hacia la unidad de los distintos saberes.

Entre la apertura y el cierre de su catálogo, Sarmiento desarrolla una presentación alfabética de las disciplinas, en la que a través de letras mayúsculas y minúsculas especifica ciencias y materias, entendidas estas últimas como partes de una ciencia o disciplinas sin método científico. La carencia de un sistema de clasificación entre ellas, al modo habitual en el período a través de clases y subclases, debe entenderse como la plasmación de las dificultades encontradas para ordenar una ciencia en proceso de especialización, como también indican algunos reenvíos en el sistema de referencias incluidos en los registros. Tal problema es característico del siglo, y como señalamos tiene su más conocida representación en la Encyclopédie francesa.

También la ordenación interna dentro de cada ciencia o materia resulta significativa. Sarmiento dispone con carácter general el inicio de cada epígrafe con los libros de los autores más antiguos que posee, o con colecciones de los mismos. Claramente intenta, con las limitaciones propias de las futuras incorporaciones de obras a su biblioteca, representar el desarrollo histórico del conocimiento humano.

La composición de su biblioteca no es menos representativa que el orden de los libros en relación a sus intereses, bien patentes en sus escritos: los estudios filológicos, el método matemático y experimental, y la búsqueda de la "felicidad pública”, plasmada en el logro del avance económico, social y científico de la nación española. A través de las citas que hace en sus escritos, incluido el propio catálogo, conocemos el uso filológico que ha hecho de sus libros teológicos, de sus colecciones de erudición oriental, de sus libros de historia natural, de sus fuentes jurídicas, etc., de forma que podemos decir que es también en ellos, además de en los fondos propiamente lexicográficos, donde ha obtenido gran parte de la información sobre la que ha elaborado sus aportaciones filológicas. Los libros de ciencias y artes han nutrido sus obras botánicas y médicas, y las matemáticas, componente esencial de su método, haciendo también uso de estos libros en sus trabajos etimológicos. Su interés primordial por la historia, característica de los intereses ilustrados en defensa de las naciones-estado, se muestra en la amplitud de los libros de esta clase, a la que numéricamente tanto contribuyen sus colecciones de historia literaria, una disciplina que intentaba sistematizar la historia del conocimiento y sus instituciones y poner orden y control en el conjunto del saber. Distinguir para unir.

\section{NOTAS}

${ }^{1}$ El político y científico Vicente Vázquez Quiroga Queipo de Llano (1804-1893) fue elegido académico de la Historia en 1860 y tomó posesión el 27 de octubre de 1861, aproximadamente un año antes de que firme la nota en el manuscrito. Unos años más tarde, dona algunos libros y antigüedades a la Academia, y en la carta de ofrecimiento de la nueva donación recuerda la entrega del catálogo de la biblioteca de Sarmiento.

${ }^{2}$ Para explicar tal influencia, además de la lectura de sus obras, hay que tener en cuenta que Sarmiento coincide con benedictinos que mantenían contactos con los maurinos, como Juan Bautista Lardito, abad de San Martín de Madrid cuando Sarmiento toma el hábito y al que dedica una extensa nota biográfica en su catálogo, Manuel Navarro, con quien colaboró en sus años de formación en Salamanca, y Antonio Alejandro Sarmiento de Sotomayor, abad de Samos y posteriormente general de la Congregación de Valladolid.

${ }^{3}$ Dejamos fuera de este análisis los registros y volúmenes del epígrafe Miscelánea, ya que su adscripción a una u otra clase debería hacerse título a título, lo que implicaría una asignación ucrónica. 


\section{BIBLIOGRAFÍA}

Academia Española. Nuevo Tesoro lexicográfico de la lengua española [en línea]. <http://www.rae.es/recursos/diccionarios/diccionarios-anteriores-1726-1992/nuevo-tesoro-lexicografico> [Consulta: 15 de septiembre de 2015].

AGUILAR PIÑAL, F. Bibliografía de Autores españoles del siglo XVIII. Madrid: Consejo Superior de Investigaciones Científicas, 1981-2001, v. VII.

ALEMBERT, J. d' Discours préliminaire des éditeurs de 1751 et articles de l'encyclopédie introduits par la querelle avec le Journal de Trévoux. GROULT, M. (ed.). Paris: Honoré Champion, 1999.

BOUZA, F. Corre manuscrito. Una historia cultural del siglo de Oro. Madrid: Marcial Pons, 2001.

CASTELLANOS DE LOSADA, B.S. Voz Sarmiento. En: Biografía eclesiástica completa: vida de los personajes del Antiguo y Nuevo Testamento. Madrid: Alejandro Gómez Fuentenebro, 1865, v. XXVI.

DE BENI, M. Las voces “Astronomía” y “Astrología” en el siglo XVIII español. En: SANTOS ROVIRA, J. M. (ed.). Ensayos de Lingüística Hispánica. Lisboa: Sinapis, 2014, p. 273-288.

DÍAZ Y DÍAZ, M.C. El Códice Calixtino de la Catedral de Santiago de Compostela: estudio codicológico y de contenido. Santiago de Compostela: Centro de Estudios Jacobeos, 1988.

DURAN LÓPEZ, F. Vidas de sabios. El nacimiento de la autobiografía moderna en España (1733-1848). Madrid: Consejo Superior de Investigaciones Científicas, 2005.

ENCISO RECIO, L.M. Barroco e ilustración en las bibliotecas privadas españolas del siglo XVIII. Madrid: Real Academia de la Historia, 2002.

GARCÍA MELERO, J.E. El arquitecto académico a finales del siglo XVIII. Espacio, Tiempo y forma, Serie VII Historia del Arte, 1997, t. 10, p. 161-216.

GARCÍA MORALES, J. Un informe de Campomanes sobre las bibliotecas españolas [1788]. Revista de Archivos, Bibliotecas y Museos, 1968-1972, t. LXXV, 1-2, p. 91-126.

LÓPEZ PELÁEZ, A. La librería del P. Sarmiento. Tierra gallega, 1895, t. II, 75, p. 3-4.

MONTEAGUDO, H. Martín Sarmiento en el Correo Literario de la Europa (1782). Unha nova achega á súa bibliografía dezaoitesca. En: SANTAMARINA, A. (ed.) Frei Martín Sarmiento. Santiago de Compostela: Universidade, 2002a, p. 77-97.

MONTEAGUDO, H. Limiar. En: SARMIENTO, M. Catálogo de algunos libros curiosos y selectos, para la librería de algun particular, que desee comprar de tres á quatro mil tomos. Noia: Editorial Toxosoutos, 2002b, p. 7-56.

PONZ, A. Viage de España, en que se da noticia de las cosas más apreciables, y dignas de saberse, que hay en ella ( $2^{\mathrm{a}}$ ed.) Madrid: Joaquín Ibarra, 1782, v. V.

SANTOS PUERTO, J. El padre Sarmiento y la introducción de Newton en España. Llull. Revista de la Sociedad Española de Historia de las Ciencias y de las Técnicas, 1997, t. 20, 39, p. 697-734.

SANTOS PUERTO, J. Martín Sarmiento: Ilustración, educación y utopía en la España del siglo XVIII. A Coruña: Fundación Pedro Barrié de la Maza, 2002.

SARMIENTO, M. Noticia de Varios Còdices M.Stos. è impresos, y observaciones hechas por el Pe. Maestro Sarmiento en su letùra. S.f. AGFCMS, Col. Medinasidonia, t. II, f. 147-586.

SARMIENTO, M. Bibliotheca de la Santa Yglesia de Toledo. Borrador de los Libros que en ella registré el año de 1727. 1727. AGFCMS, Col. Medinasidonia, t. IV, f. 27-73.

SARMIENTO, M. Biblioteca de algunos Libros curiosos que compraria si tuviera dinero... que no hay en San Martín. 1730a. MP, Col. Medinasidonia, t. II, f. 558-570.

SARMIENTO, M. Citas de algunos Autores Curiosos que leí de verbo ad verbum desde $1^{\circ}$ de Enero de $1730.1730 \mathrm{~b}$. AGFCMS, Col. Medinasidonia t. II, f. 432-534.

SARMIENTO, M. Apuntamientos para realizar una empresa...que pueda servir para la nueva Academia MédicoMatritense... 1734? AGFCMS, Col. Medinasidonia, t. V, f. 48-72.

SARMIENTO, M. Catálogo de los Autores de quienes yo fr. Martín Sarmiento Benedictino tengo ad usum, ó todas sus obras, ó parte de ellas... 174?-176? RAH, Ms. 9/1829.

SARMIENTO, M. Carta de Martín Sarmiento al Abad de Samos, 25 de marzo de 1750. AGFCMS, Col. Medinasidonia, t. VIII, f. 372-389.

SARMIENTO, M. Notas al Privilegio de Ordoño II. 1752. AGFCMS, Col. Medinasidonia, t. XVIII, f. 42-293.

SARMIENTO, M. Papel curioso sobre la planta que en Galicia es muy común y se llama Seyxebra... 1762. AGFCMS, Col. Medinasidonia, t. XI, 428-711.

SARMIENTO, M. Catálogo de los Pliegos, que yo Fray Martín Sarmiento, Benedictino,..., he escrito de mi mano, pluma, y letra, sobre diferentes asuntos. 1767. BNE, Ms. 17642.

SARMIENTO, M. Sobre Methodo de Estudios. 1769. AGFCMS, Col. Medinasidonia, t. VI, f. 283-327.

SARMIENTO, M. Memorias para la historia de la Poesía y Poetas españoles.... Madrid: Joachin Ibarra, 1775. 
SARMIENTO, M. Cartas al Duque de Medinasidonia, 1747-1770. SANTOS PUERTO, J. (ed.). Ponferrada: Instituto de Estudios Bercianos, 1995.

SARMIENTO, M. Catálogo de algunos libros curiosos y selectos, para la librería de algun particular, que desee comprar de tres á quatro mil tomos. MONTEAGUDO, H. (ed.). Noia: Editorial Toxosoutos, 2002a.

SARMIENTO, M. Reflexiones literarias para una Biblioteca Real (A referencia cultural da Ilustración española). SANTOS PUERTO, J. (ed.). Santiago de Compostela: Consello da Cultura Galega, 2002b.

SARMIENTO, M. Sistema de adornos del Palacio Real de Madrid. ÁLVAREZ BARRIENTOS, J., HERRERO CARRETERO, C. (ed.). Madrid: Sociedad Estatal de Conmemoraciones Culturales, 2002c.

STIFFONI, G. La biblioteca de Fray Martín Sarmiento. En: Homenaje al Profesor Carriazo. Sevilla: Universidad de Sevilla, Facultad de Filosofía y Letras, 1973, v. III.

VÁLGOMA Y DÍAZ-VARELA, D. de la. El inédito catálogo de la Biblioteca del Padre Sarmiento, Don Vicente Vázquez-Queipo y un singular “exlibris” de Fray Martín. Boletín da Real Academia Galega, 1971-1972, 353-354, p. 143-147.

VÁZQUEZ QUEIPO, V. Carta en la que notifica la donación de un conjunto de libros y manuscritos inéditos. 13 de marzo de 1865. RAH, Ms. Ga 1865/3(1).

VERNER, M. Adrien Baillet (1649-1706) and his Rules for an Alphabetic Subject Catalog. Library Quarterly, 1968, 38, 3, 217-230.

\section{Siglas}

AGFCMS. Archivo General de la Fundación Casa Medina Sidonia

MP. Museo de Pontevedra

BNE. Biblioteca Nacional de España

RAH. Real Academia de la Historia 


\section{Apéndice I}

\section{CIENCIAS Y MATERIAS}

BIBLIAS. Versiones y Concordancias

Concordancias

Aparato, Critica y Erudicion de la Escritura

CONCILIOS. Padres y Dogmaticos

THEOLOGIA Escolastica y Moral

ASTROLOGIA y Artes Vanas

Cirugia

Chrysopeya, Chimica y Secretos

Cosmographia, Astronomia y Gnomonica

CRÍTICOS. Philòlogos y Observadores

DERECHO Civil, Leyes y Ordenanzas

DERECHO Canonico, Bulas y Constituciones

ERÍSTICOS. Apologèticos y Satyricos

Erudicion Oriental

Buxtorfios

Hottingero

Seldeno

Relando

Vossios

Genealogìas. Sellos y Blasón

Geografia y Nautica

Geometria Practica. Estatica y Mechanica

Música. Theorica y Practica

GRAMMATICA. Lengua Castellana

Lengua Portuguesa

Lengua Vascongada

Lenguas Exoticas. De la America

De Africa

De Asia

De Europa

GRAMMATICA. Lengua Italiana

Lengua Francesa

Lengua Inglesa

Lengua Flamenca

Lengua Alemana

\section{REGISTROS}

57

25

59

80

85

45

16

15

81

14

29

37

105

45

19

13

13

6

0

1

\section{VOLÚMENES}

120

38

105

135

155

52

20

18

88

20

36

67

110

57

19

16

15

8

13

30

145

24

19

23

24

6

0

1

6

19

19

6

3

10 
CIENCIAS Y MATERIAS

Lengua Húngara

GRAMMATICA. Lengua Griega

Lengua Grièga Vulgàr

GRAMMATICA. Lengua Latina

HISTORIA de la AMÉRICA, ASIA y AFRICA

História Byzantîna de Parîs. Con Adiciònes

HISTORIA. Ecclesiastica y Monastica

HISTORIA de España

HISTORIA. Grièga y Romana

HISTORIA Literaria. Juègos Grandes, y Periodicos

Vidas y Bibliotecas

HISTORIA. De Naciones Varias

HISTORIA NATURAL, Botanica y Agricultura

HISTORIA. De Portugàl

Inscripciones, Medallas y Antigüedades

LITURGIA Ascetica y Mystica

MATHEMATICAS. Arithmetica, Geometria y Algebra

MEDICINA. Cirujía y Chymica

Meùrsio

Fabricio

MISCELÁNEOS

Novèlas y Libros de Cavallerìa

Optica, Perspectiva y Pintura

Architectura Civil y Militar

PHILOSOPHIA Antigua

PHILOSOPHIA Moderna

PHILOSOPHIA. Moral, Ethica y Symbolica y Mythologìa

POESIA. Poètas Griègos

Poetas Latinos Antiguos

Poètas Castellános

Poetas Portugueses

Poetas Lemosinos

Poètas Italiános

Poetas. Latinos Modernos

POLÍTICA. Economica y Comercio

RETHORICA. Oratoria y Epistolas

Tomitos DE REPUBLICAS. Con Apéndizes

VIAGES Antiguos y Modernos

\section{REGISTROS}

1

32

5

72

51

41

59

87

46

15

84

97

212

19

119

88

107

137

42

13

41

42

21

23

56

74

28

22

67

82

11

4

49

68

30

28

78

73
VOLÚMENES

1

38

5

81

60

58

181

122

65

517

219

182

301

27

151

126

142

177

42

40

62

43

29

26

77

175

40

32

80

104

13

4

51

83

58

43

83

251 
CIENCIAS Y MATERIAS

VIDAS

OBRAS de los Monxes, De San Mauro Achery

Mabillon

Marténe

Sta. Martha

Martianay

Montfaucon

Delarue

Pe. Kircher

Pe. Schotto

Caramuèl
REGISTROS

55

1

8

5

2

1

12

20

14

12

35
VOLÚMENES

62

3

26

20

12

5

46

41

18

19

50 